\title{
A Study on Corruption and Auditing Strategies of Related Party Transactions of Listed Companies
}

\author{
Liu Bo ${ }^{1, *}$ Wang Yilin ${ }^{2}$ Guo Chenyu ${ }^{3}$ \\ ${ }^{1}$ School of Accounting, Shanxi University of Finance \& Economics, Shanxi, Taiyuan 030000, China \\ ${ }^{2}$ School of Finance and Public Economics, Shanxi University of Finance \& Economics, Shanxi, Taiyuan 030000, China \\ ${ }^{3}$ School of Economics, Shanxi University of Finance \& Economics, Shanxi, Taiyuan 030000, China \\ *Corresponding author. Email: xyzcpa@126.com
}

\begin{abstract}
Related party transactions, as an important part of the trading model of listed companies, have an important impact on corporate stakeholders. Related party transactions can reduce the transaction costs of enterprises and continuously promote the development of a market economy. However, most of the profit manipulation of listed companies is through related party transactions. This article takes Jilin Zixin Pharmaceutical Co., Ltd. as an example, sorts out the main methods of financial fraud in related party transactions of listed companies, and proposes corresponding audit strategies for the problems in financial fraud in related party transactions of Zixin Pharmaceutical. The aim is to regulate the related party transactions of listed companies and promote fairness in commercial transactions.
\end{abstract}

Keywords: Zixin Pharmaceutical, related party transactions, financial fraud, audit strategy, tax avoidance

\section{INTRODUCTION}

In the context of globalization, competition between enterprises has become increasingly fierce. Under such circumstances, some enterprises use illegal methods to artificially increase profits and whitewash statements. To mislead consumers and investors. However, once the illegal means of a company are exposed, it will have an extremely bad impact on the development of the company. Today, companies often use affiliate transactions for fraud. There are two reasons. First, the accounting standards of related party transactions are not clear enough, which makes financial staff lack professionalism, and fraud of related party transactions may occur. Second, listed companies conceal related party transactions in order to increase profits and cash flow. The disclosure of accounting information is required, and the core information of the transaction, such as the nature, amount and content, is ambiguous.

\section{CONCEPTS AND TYPES OF RELATED PARTY TRANSACTION FRAUD}

Corruption in related party transactions refers to a misleading behavior of the users of the statement by listed companies in order to control profits and make up for losses through related transactions, and fail to properly or fully disclose in statements and notes. In general, listed companies use the following types of related party transactions to manipulate profits.

\subsection{Corruption In Related Purchases And Sales}

Corruption in the purchase and sale of affiliated companies means that listed companies engage in fraud through purchase and sales activities between related parties, including deliberately fictional economic business, concealment, alteration, falsification of documents or vouchers, multiple reconciliations of an economic business, and deliberate confusion.

\subsection{Entrusted Management Fraud}

Entrusted management fraud means that the listed company takes advantage of the system deficiencies of related laws and regulations and uses custody management to manipulate profits. In practice, listed companies usually entrust non-performing assets to related parties to operate and receive high returns based on the price agreed between the two parties.

\subsection{Fraud In Capital Transactions}

Fraud in capital transactions means that the listed company borrows the funds raised to the parent company or other related parties that are not included in the consolidated statement, and collects capital occupation fees at the agreed high interest rate, thereby falsely increasing profits. 


\subsection{Fraudulent Methods Of Related Party Transactions Of Zixin Pharmaceutical Company}

Cost-sharing fraud means that there is an agreement between the listed company and the group company on the payment and sharing of expenses, and the purpose of adjusting profits is achieved by manipulating the sales expenses and management expenses that should be shared with the related parties.

\section{OVERVIEW OF FRAUD AND RELATED METHODS OF RELATED PARTY TRANSACTIONS IN ZIXIN PHARMACEUTICAL}

\subsection{Cases Of Fraud In Related Party Transactions Of Zixin Pharmaceutical Company}

The full name of Zixin Pharmaceutical Co., Ltd. is Jilin Zixin Pharmaceutical Co., Ltd., which was established in 1998 and listed on the Shenzhen Stock Exchange in 2007. It is a high-tech company integrating scientific research, development, production, sales, and cultivation of medicinal plants Technology joint-stock enterprises. It currently has 9 wholly-owned subsidiaries, 2 holding subsidiaries, and 1 participating company. "Taking people with quality and brewing medicine with virtue" has always been the respected purpose of Zixin Pharmaceutical. In 2010, Zixin Pharmaceutical entered the ginseng industry and achieved amazing results. Within a year, its operating income and net profit have doubled. However, on August 16, 2011, an article published by the Shanghai Securities News revealed a case of fraud in related party transactions of Zixin Pharmaceutical. On October 19, 2011, the CSRC filed an investigation into Zixin Pharmaceutical. After investigation, Zixin did indeed violate the law by falsely increasing revenue and profits through related party transactions. On February 13, 2014, the CSRC issued the "Administrative Punishment Decision", which punished Zixin Pharmaceutical and nine responsible persons, including Guo Chunsheng and Cao Enhui. At the same time, the China Association of Examiners inspected the Zhongzheng Certified Public Accountants, which is responsible for the audit of Zixin Pharmaceutical's annual report, and found that its signed CPA did not maintain due professional suspicion during the audit. There were improper aspects in the acquisition of evidence and the formation of audit conclusions. In the end, the CICPA issued a disciplinary comment on the signed CPAs Liu Kun and Zhang Zhongwei.

\subsubsection{Fictional downstream customer}

According to the 2010 annual report of Zixin Pharmaceutical, the top five customers of the company's operating income are Sichuan Pingda Biological Products Co., Ltd., Yinzhou Qian Herbal Medicine Beverage Factory, Jilin Zhengde Pharmaceutical Co., Ltd., Tonghua Lifa Ginseng Trade Co., Ltd., and Tonghua Wenbo Ginseng Trading Co., Ltd. These five companies brought a total of 230 million operating income to Zixin Pharmaceutical in 2010, accounting for $36 \%$ of Zixin Pharmaceutical's operating income that year. However, according to Zixin Pharmaceutical's periodic reports over the years, none of the above companies have been disclosed. Compared with the 2009 annual report, the total purchase amount of the top five customers of Zixin Pharmaceutical was less than 27 million yuan, accounting for only $10 \%$ of the operating income of the year. And also in 2010, the performance of the five major customers "birthless", and their background is quite "mysterious". After investigation, it was found that a number of companies were confirmed to have a close relationship with Zixin Pharmaceutical, and Guo Chunsheng, the chairman of Zixin Pharmaceutical, was the link that linked them together.

\subsubsection{Virtual upstream vendor}

In addition to its downstream customers being affiliated companies of Zixin Pharmaceutical, its upstream suppliers and Zixin Pharmaceutical have inextricably related relationships. The four family members of Zixin Pharmaceutical's upstream customers, "Yanbian Jiayi", "Yanbian Yaoyu", "Yanbian Xinxin" and "Yanbian Jinhui", have caused high suspicion from the outside world. Their time of establishment, business scope, and company residence are very similar: they were all established in 2010 , and their business scope is the same as "ginseng and ginseng rough processing". The original residences were also located in the emerging industrial concentration area of Yanbian Prefecture. The ultimate controlling party is Guo Chunsheng. It is difficult to ignore the shadows of Zixin Pharmaceutical and its affiliates in the registration, change, executives, shareholders and other information of these companies, but these have not been fully disclosed in Zixin Pharmaceutical's annual report. 
2010, the operating income and net profit increased accordingly. However, the trends of the two financial indicators have been abnormal. From 2007 to 2011, net profit showed a steady increase, but operating income in 2011 showed a rapid increase compared to 2008 and 2009 , and even reached 4.15 times the operating income in 2007. This abnormal change indirectly indicates that there may be false related party transactions in Zixin Pharmaceutical.

\section{and profits}

3.3.1. Abnormal changes in operating income

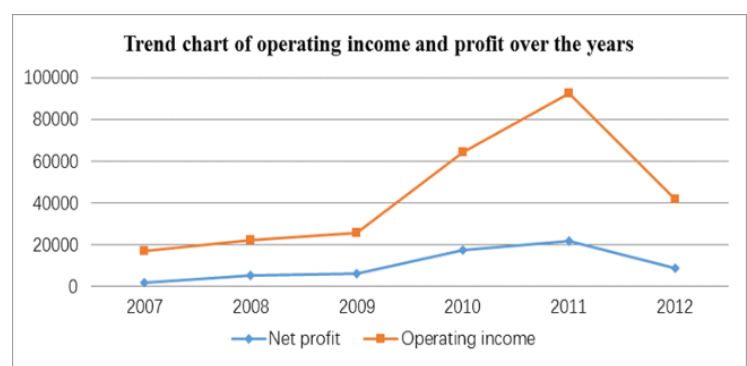

Figure 1 Trend of operating income and profit changes over the years

As shown in Figure 1, the operating income and profit of Zixin Pharmaceutical from 2007 to 2009 were relatively stable, and its net profit fluctuated between 50 million and 60 million yuan. After expanding the ginseng business in

Table 1 Summary of related financial data of Zixin Pharmaceutical over the years

\begin{tabular}{lllllll}
\hline Project & $\mathbf{2 0 0 7}$ & $\mathbf{2 0 0 8}$ & $\mathbf{2 0 0 9}$ & $\mathbf{2 0 1 0}$ & $\mathbf{2 0 1 1}$ & $\mathbf{2 0 1 2}$ \\
\hline Operating cash flow & 2,129 & 2,567 & 1,281 & $-21,542$ & $-55,872$ & $-19,545$ \\
accounts receivable & 5,990 & 7,773 & 12,622 & 13,910 & 54,946 & 22,954 \\
stock & 1,558 & 3,043 & 3,049 & 17,304 & 85,094 & 141,564 \\
Net profit & $4,794.85$ & $5,333.97$ & $6,107.88$ & $17,317.36$ & $21,729.00$ & $8,631.14$ \\
\hline
\end{tabular}

Both Zixin Pharmaceutical's operating income and net profit have grown significantly and should have good profitability. In this case, there are two possibilities for a negative net cash flow, namely that the goods are mainly sold through credit or bulk purchases of raw materials. However, it can be seen from Table 1 that the accounts receivable of Zixin Pharmaceutical in 2010 did not increase significantly compared with 2009 , and the changes in inventory and net profit were basically the same. Therefore, through the analysis of the above financial data, we can conclude that there may be false related party transactions in Zixin Pharmaceutical.

\section{ANALYSIS AND AUDIT STRATEGY OF ZIXIN PHARMACEUTICAL RELATED PARTY TRANSACTION FRAUD}

\subsection{Motivation Analysis Of Related Party Fraud In Zixin Pharmaceutical}

\subsubsection{External cause analysis}

The financial fraud of Zixin Pharmaceuticals once again revealed the failure of the supervision of the securities market. The institutional loopholes in the stock market need to be urgently improved, and the system construction of the securities market has a long way to go. The certified public accountant signed by Zhongzheng Certified Public Accountants hired by Zixin Pharmaceutical did not maintain due professional skepticism in the project audit process, and was involved in the planning and implementation of audit procedures, the acquisition of audit evidence, and the formation of audit conclusions. There are deficiencies in the implementation of preliminary business activities and risk assessment processes. Issued a standard 
unqualified audit report on Zixin Pharmaceutical's annual report in the absence of appropriate and adequate audit evidence on revenue, related party transactions, and prepayments, in violation of the Chinese Certified Public Accountants' auditing standards and professional ethics is a typical audit failure. It is precisely because the regulatory authorities have not paid enough attention to the bad effects caused by financial fraud, and their penalties have not played an effective deterrent effect on listed companies, which has made listed companies wantonly and exacerbated financial fraud.

\subsubsection{Internal cause analysis}

(1) The unreasonable shareholding structure leads to the imperfect corporate governance structure. The first two shareholders of Zixin Pharmaceutical are Dunhua Kangping Investment Co., Ltd. and natural person shareholder Zhong Weiguang. Among them, the three major shareholders of Dunhua Kangping Investment Company have special relatives with Guo Chunsheng, the chairman of Zixin Pharmaceutical, and the second largest shareholder also has a close relationship with Guo Chun. It is not difficult to find that Guo Chunsheng is the actual controller of Zixin Pharmaceutical, and holds the lifeblood of Zixin Pharmaceutical. Therefore, Zixin Pharmaceutical's shareholding structure is actually "one dominant company", and the lack of interest constraints between shareholders makes Guo Chunsheng have absolute decision-making power over the company's production and operation, which creates opportunities for financial fraud.

(2) The internal controller is obvious. The company is under the control of internal management, which makes shareholders' rights virtually suspended. Guo Chunsheng, the chairman of Zixin Pharmaceutical, is not only the actual controller of Zixin, but also the general manager. It combines control, execution and supervision. Internal control is invalid in this case. The control of top management even facilitates joint fraud with management. Therefore, "Yanbian Department" and "Tonghua Department" have conducted financial fraud through selfbuying and selling.

Table 2 Statistics of corporate governance

\begin{tabular}{ccccc}
\hline year & $\begin{array}{c}\text { Board of } \\
\text { Directors }\end{array}$ & $\begin{array}{c}\text { Number of } \\
\text { independent } \\
\text { directors }\end{array}$ & $\begin{array}{c}\text { Number of } \\
\text { directors and } \\
\text { management }\end{array}$ & $\begin{array}{c}\text { Number of } \\
\text { supervisors }\end{array}$ \\
\hline $\mathbf{2 0 0 6}$ & 7 & 3 & 3 & 3 \\
$\mathbf{2 0 0 7}$ & 7 & 3 & 3 & 3 \\
$\mathbf{2 0 0 8}$ & 8 & 4 & 3 & 3 \\
$\mathbf{2 0 0 9}$ & 8 & 3 & 3 & 3 \\
$\mathbf{2 0 1 0}$ & 10 & 5 & 3 & 3 \\
\hline
\end{tabular}

(3) Independent directors did not exercise due supervision functions. In fact, Zixin Pharmaceutical has always had independent directors. However, the independent directors did not comment on the company's resolutions because of frequent related transactions involving "Yanbian Department" and "Tonghua Department" of Zixin Pharmaceutical that involve significant amounts of money and abnormal accounting data. Obviously, it is not that their professional level is not enough to detect problems, but that the independent directors have not performed the supervision function. The so-called independent directors of Zixin Pharmacy are virtually useless, making the leaders of financial fraud unscrupulous.

(4) The company's internal supervisory board and audit department have no names. The company's supervisory board and internal audit department have a very important role in overseeing the company's finances and other activities related to company management. These two departments, as internal organizations of the company, should better understand the company's various economic activities and find problems more easily. However, for Zixin Pharmaceutical, these two departments have not formed obstacles to financial fraud of Zixin Pharmaceutical. In this process, we can understand that the supervisory board and the internal audit department failed to perform their supervisory functions, and even facilitated financial fraud.

\subsection{Analysis Of The Reasons For Zixin Pharmaceutical's Related Party Transaction Fraud Audit Failure}

\subsubsection{Risk-oriented auditing standards are not in place}

Modern risk-oriented auditing requires the auditor to identify, evaluate and deal with related party transactions as much as possible. First, Zhongzhan Certified Public Accountants failed to implement the above steps to ensure the accuracy of the audit information. Zixin Pharmaceutical increased operating profit by concealing related party transactions, making the data in its financial statements significantly higher than the level in the same industry. In such circumstances, professional auditors should maintain professional skepticism. Therefore, it is very likely that auditors will omit the risk-oriented auditing standards in the audit process. Second, auditing standards require auditors 
to review all audit evidence, especially those that contain evidence of significant transactions. From 2009 to 2010, Zixin Pharmaceutical's top five suppliers brought in revenues ranging from $10 \%$ to $36 \%$, and the names of the suppliers were different between these two years. The suppliers out of nothing are worthy of the doubt and indepth study of CPAs.

\subsubsection{Fraud risk is not identified properly}

Corruption of related party transactions is a common cause of CPA audit failures. Auditors must not only collect as much audit evidence as possible to support their investigation, but also identify the authenticity of the audit evidence. Sichuan Pingda Biological Company is the largest customer of Zixin Pharmaceutical. In 2010, Pingda's operating income was only 30.11 million yuan, but it spent more than 70 million yuan to purchase Zixin Pharmaceutical's ginseng. This is an incredible thing. If the CPA can notice this, it will be difficult for Zixin Pharmaceutical to complete the related party transaction fraud so smoothly.

\subsubsection{Inadequate implementation of analytical review procedures}

Auditing standards require auditors to perform analysis procedures on related party transactions and carefully review the information provided by the audited unit to determine the completeness and fairness of related party transactions. At the end of the audit, a general review of the statements is also required. If Zhongzheng Certified Public Accountants investigates the related party relationship of Zixin Pharmaceutical according to the analysis procedure, then this behavior can be corrected. In just one year, the profits of Zixin Pharmaceutical exceeded the two giant ginseng giants. However, in 2010, Zixin Pharmaceuticals was unable to make ends meet. These signs indicate that auditors have not paid much attention to abnormal business activities. The investigation report of the China Association of Commentaries also showed that the signing auditors of Zonzen Certified Public Accountants lacked the implementation of due audit procedures in many aspects. The CPA despise the execution of the risk assessment, so that there is no appropriate audit evidence to support its abnormal data in the purchase and sale process. The above facts indicate that auditors violated professional ethics and standards

\subsection{Auditing Strategies for Corruption in Related Party Transactions}

\author{
4.3.1. In the initial stage of audit risk assessment, \\ special attention should be paid to related party \\ fraud
}

In the initial stage of the audit risk assessment, the CPA should fully understand the daily business activities, financing and investment activities, ownership and organizational structure of the audited unit, and focus on related parties based on professional suspicions to obtain sufficient audit evidence and make correct Professional judgment. Zixin Pharmaceutical's shareholding structure shows a dominant position. Guo Chunsheng's wife and mother own $2.42 \%$ and $43.4 \%$ of the shares, respectively. Others are basically held by relatives, and the control of management and supervision is in the hands of the chairman. Zhongzhan Certified Public Accountants did not pay special attention to this phenomenon. At the risk assessment stage, the auditor of Zhongzhan Certified Public Accountants should first review the related parties involved in the previous annual report and determine whether the relationship has changed. Secondly, auditors should look at the huge new financial investments that year to see if there are new connections. Finally, consider asking about the main family relationships of important employees of the audited unit, the names and details of the affiliated companies, and judging the possibility of an association between senior management and the company.

\subsubsection{Implement further audit procedures based on understanding of internal controls}

Fraud risk also has its own laws, that is, it will be affected by the combination of factors such as the motivation of business management needs, the pressure of external industry competition, or other rationalized explanations. Generally speaking, the poor performance of the audited company exacerbates the risk that management hopes to change the company's risk of loss through shortcuts of related party fraud. At this time, the internal audit department and external independent directors should play the role of supervising the illegal transactions of senior management personnel. However, Zixin Pharmaceutical's internal control and other supervision are controlled by Chairman Guo Chunsheng, so they can only turn a blind eye to their related party transactions. Against this background of industry culture, auditors should understand at the beginning of the project whether there are reasonable control procedures for the authorization and approval of related party transactions, and whether the transaction details are fully identified and accurately disclosed, especially the handling of violations during the transaction. Or directly check the related party transaction documents and appointment of the supervisory board and independent 
[2] Chen Hui.Financial fraud analysis of listed

directors. In short, the auditor should check all factors that may affect the internal control of the auditee, improve the reliability of audit evidence, and reduce the risk of audit failure.

\subsubsection{Strengthen the overall analysis and review of related parties}

There are many problems with related transactions of Zixin Pharmaceutical, but Zhongzhan Certified Public Accountants has issued inappropriate audit reports for many years, indicating that the auditors issued the final report without rigorous review. At the stage of issuing the audit report, the auditing standards clearly require the overall review of the annual report through the analysis process, especially if it is not easy to determine the related party transactions, a three-level review should be performed, that is, the project leader, department head and company The person in charge reviews them one by one. The signing CPA should fully consider whether the audited entity should truthfully and reliably disclose the related parties and their transactions in the annual report in accordance with the standards, and fully consider the types of opinions in the audit report. Only when the certified public accountant fully examines the various possibilities that the audited party can use the related party transactions to implement fraud and adopts corresponding auditing strategies for verification, and proposes appropriate audit opinions, can the audit risk be reduced to an acceptable low level.

\section{CONCLUSION}

In view of the frequently-occurring cases of related party transaction fraud in listed companies in the capital market in recent years, based on the introduction of related party transaction fraud related theories, this article takes Jilin Zixin Pharmaceutical's related party transaction fraud as a case study object. Starting from the means of identification, the causes of fraud in related party transactions and the reasons for audit failures of accounting firms were analyzed, and specific auditing strategies were proposed based on this, which provided guidance for identifying listed companies' fraud in related party transactions and standardized the association of listed companies The party transaction audit provides a reference for the purpose of promoting the stable and healthy operation of the capital market.

\section{REFERENCES}

[1] Zhang Jingting.Analysis of the Causes and Means of Financial Fraud in Listed Companies in China [J]. Accounting of China Township Enterprises, 2016, (8): 102-103.doi: 10.3969 / j. issn.1004-8480.2016.08.053. agricultural companies based on the fraud triangle theory [J]. Southern Agricultural Machinery, 2016,47 (4): 44-44.doi: 10.3969 / j. issn.1672-3872.2016.04.035.

[3] Guan Yilin. Causes of financial fraud in Nanyang shares $[\mathrm{J}]$. Accounting of China Township Enterprises, 2017,0 (2): 76-77.doi: 10.3969 / j. issn.10048480.2017.02.039. 